\title{
Crescimento e produção de espécies forrageiras consorciadas com pinhão-manso
}

\author{
João Alfredo Neto da Silva(1), Cristiano Márcio Alves de Souza(1), \\ Cesar José da Silva(2) e Simone Priscila Bottega ${ }^{(1)}$
}

\begin{abstract}
(1)Universidade Federal da Grande Dourados, Faculdade de Ciências Agrárias, Rodovia Dourados-Itahum, km 12, Caixa Postal 322, CEP 79804-970 Dourados, MS. E-mail: silvaneto20@yahoo.com.br, csouza@ufgd.edu.br, sibottega@hotmail.com (2)Embrapa Agropecuária Oeste, BR 163, km 253,6, Caixa Postal 661, CEP 79804-970 Dourados, MS. E-mail: silvacj@cpao.embrapa.br
\end{abstract}

\begin{abstract}
Resumo - O objetivo deste trabalho foi avaliar o crescimento e a produção de matéria seca de espécies forrageiras consorciadas com pinhão-manso (Jatropha curcas). O experimento foi realizado no Município de Dourados, MS, em delineamento de blocos ao acaso, em arranjo fatorial 7x2, com parcelas subdivididas no tempo. As espécies avaliadas foram: Stylosanthes spp.; Urochloa ruziziensis; U. ruziziensis + Stylosanthes spp.; U. humidicola; Megathyrsus maximus 'Massai'; Cajanus cajan; e Crotalaria spectabilis. O desempenho das espécies foi avaliado nos sistemas de cultivo solteiro e consorciado com pinhão-manso. O pinhão-manso foi plantado em novembro de 2006, no espaçamento $3 \times 2 \mathrm{~m}$, e as forrageiras foram semeadas nas entrelinhas, em março de 2009. A avaliação foi realizada em sete épocas, de abril de 2009 a junho de 2010. As espécies apresentaram boa capacidade produtiva, para uso como forrageiras ou em cobertura do solo, em consórcio com pinhão-manso. O capim-massai (M. maximus) apresenta maior capacidade produtiva e tolerância ao sombreamento do que as demais espécies, quando consorciado com pinhão-manso.
\end{abstract}

Termos para indexação: Jatropha curcas, capim-massai, plantas de cobertura, tolerância ao sombreamento.

\section{Growth and production of forage species intercropped with physic nut}

\begin{abstract}
The objective of this work was to evaluate growth and dry matter production of forages species intercropped with physic nut (Jatropha curcas). The experiment was carried out in Dourados, MS, Brazil, in a randomized complete blocks design, in a factorial arrangement $7 \times 2$, split-plotted in time. The evaluated species were: Stylosanthes spp.; Urochloa ruziziensis; U. ruziziensis + Stylosanthes spp.; U. humidicola; Megathyrsus maximus 'Massai'; Cajanus cajan; and Crotalaria spectabilis. Species performance was evaluated in single and in physic nut-intercropped systems. Physic nut was planted in November/2006, in a 3x2-m spacing, and forages were sown in between rows in March/2009. The evaluations were done in seven periods, from April/2009 to June/2010. The forage species show good productive ability both as forage and soil coverage, when intercropped with physic nut. 'Massai' grass (M. maximus) has a better productive capacity and is more tolerant to shading than the other species, when intercropped with physic nut.
\end{abstract}

Index terms: Jatropha curcas, 'Massai' grass, cover crops, shading tolerance.

\section{Introdução}

O pinhão-manso (Jatropha curcas L.) é uma espécie oleaginosa perene com possibilidade de diversificação em sistema produtivo nas propriedades agrícolas, e sua consorciação com pastagens pode ser explorada na pecuária leiteira, na de corte e na ovinocultura (Müller, 2008).

Para produção de óleo em sistemas conservacionistas, recomenda-se o cultivo de pinhão-manso em consórcio com poáceas e fabáceas nas entrelinhas. Algumas poáceas, quando utilizadas em consórcio, podem melhorar o sistema produtivo da cultura principal, por meio de melhorias física, química e biológica do solo (Alvarenga et al., 2001).

As espécies de fabáceas possuem sistema radicular pivotante, promovem a ciclagem de nutrientes, aproveitam a água das camadas subsuperficiais do solo e fixam nitrogênio (Fageria \& Stone, 2004). Já as poáceas caracterizam-se pela elevada produção de matéria seca com alta relação $\mathrm{C} / \mathrm{N}$, o que favorece a manutenção de resíduos vegetais na superfície do solo, a supressão de plantas invasoras e a diminuição da amplitude térmica do solo (Alvarenga et al., 2001).

Espécies arbustivas que apresentam abundante queda de folhas e decomposição lenta podem prejudicar o 
rebrote e o crescimento do capim (Andrade et al., 2003, 2004; Dias-Filho, 2007). Entretanto, mesmo com a possibilidade de competição, as poáceas forrageiras tropicais, tais como as braquiárias, apresentam boa adaptação ao consórcio com perenes, por possuir boa plasticidade fenotípica quanto à captura de radiação, em resposta ao sombreamento. Portanto, elas têm capacidade de manter o crescimento, mesmo com restrição de luz(Dias-Filho, 2000; Severino et al., 2006). Não obstante, a pastagem quando consorciada pode ser prejudicada pelo consórcio caso ocorra sombreamento excessivo e grande competição por água e nutrientes (Andrade et al., 2003, 2004; Dias-Filho, 2007).

Por ser uma espécie arbustiva, com rápido crescimento, com alto índice de área foliar, caducifólia e com baixa relação $\mathrm{C} / \mathrm{N}$, o pinhão-manso apresenta potencial para cultivo consorciado com forrageiras. No entanto, em sistemas de consórcio com essa espécie, os resultados são incipientes, não sendo conhecida a influência do pinhão-manso sobre as espécies cultivadas nas entrelinhas. A possibilidade de espécies arbustivas sombrearem a forrageira demonstra a necessidade de se conhecer o potencial de cada espécie, quando cultivada em sistema de consórcio.

O objetivo deste trabalho foi avaliar o crescimento e a produção de espécies forrageiras consorciadas com pinhão-manso, no Município de Dourados, no Estado de Mato Grosso do Sul.

\section{Material e Métodos}

O experimento foi instalado na Fazenda Paraíso, no Distrito de Itahum, Município de Dourados, MS $22^{\circ} 05^{\prime} 44^{\prime \prime} \mathrm{S}, 55^{\circ} 18^{\prime} 48^{\prime \prime} \mathrm{W}$ e altitude de $484 \mathrm{~m}$, em Latossolo Vermelho distrófico, com $200 \mathrm{~g} \mathrm{~kg}^{-1}$ de argila. Na Figura 1, estão apresentadas as precipitações mensais do período de desenvolvimento do trabalho e as médias históricas de precipitação pluvial.

Empregou-se o delineamento experimental de blocos ao acaso, em esquema fatorial $7 \mathrm{x} 2$, em parcelas subsubdivididas no tempo, com quatro repetições. Foram avaliadas sete espécies de forrageiras - Stylosanthes capitata + S. macrocephala (Stylosanthes spp.), Urochloa ruziziensis (Syn. Brachiaria ruziziensis), Urochloa ruziziensis + Stylosanthes spp., Urochloa humidicola (Syn. Brachiaria humidicola), Megathyrsus maximus (Syn. Panicum maximum) cultivar Massai, Cajanus cajan, e Crotalaria spectabilis - e dois sistemas de cultivo - solteiro e consorciado com pinhão-manso -, em sete épocas de avaliação.

O pinhão-manso foi implantado por semeadura direta no campo, em espaçamento de $3 \times 2 \mathrm{~m}$, em novembro de 2006. Durante os anos agrícolas 2006/2007 e 2007/2008, o talhão foi conduzido como lavoura solteira, tendo recebido os mesmos tratos culturais normalmente utilizados na cultura. Em março de 2009, as espécies forrageiras foram semeadas nas entrelinhas para a formação dos consórcios, tendo-se deixado também parcelas com forrageiras no sistema de cultivo solteiro (testemunha).

No consórcio, as parcelas com espécies forrageiras foram formadas por três entrelinhas de pinhão-manso, com $8 \mathrm{~m}$ de comprimento. As espécies forrageiras foram cultivadas em espaçamento de 0,45 m entrelinhas. Respeitou-se a distância aproximada de $0,5 \mathrm{~m}$ em cada lado da linha de pinhão-manso, para evitar competição excessiva entre plantas, bem como para facilitar a colheita e os tratos culturais. As parcelas com forrageiras no cultivo solteiro foram formadas de 15 linhas com $8 \mathrm{~m}$ de comprimento, para cada espécie.

Anualmente, realizou-se a adubação do pinhão-manso com $32 \mathrm{~kg} \mathrm{ha}^{-1}$ de $\mathrm{N}, 80 \mathrm{~kg} \mathrm{ha}^{-1}$ de P e $80 \mathrm{~kg} \mathrm{ha}^{-1}$ de $\mathrm{K}$, por meio da aplicação de $400 \mathrm{~kg} \mathrm{ha}^{-1}$ da fórmula 08-20-20. A adubação foi dividida em duas aplicações para cada safra agrícola - 50\% na primeira, em outubro de 2008 e 2009 , e $50 \%$ na segunda, em março de 2009 e de 2010. Adicionalmente, aplicou-se $50 \mathrm{~kg} \mathrm{ha}^{-1}$ de $\mathrm{N}$ na forma de ureia, em janeiro de 2009 e de 2010 . As doses e a forma de aplicação seguiram as indicações de Laviola

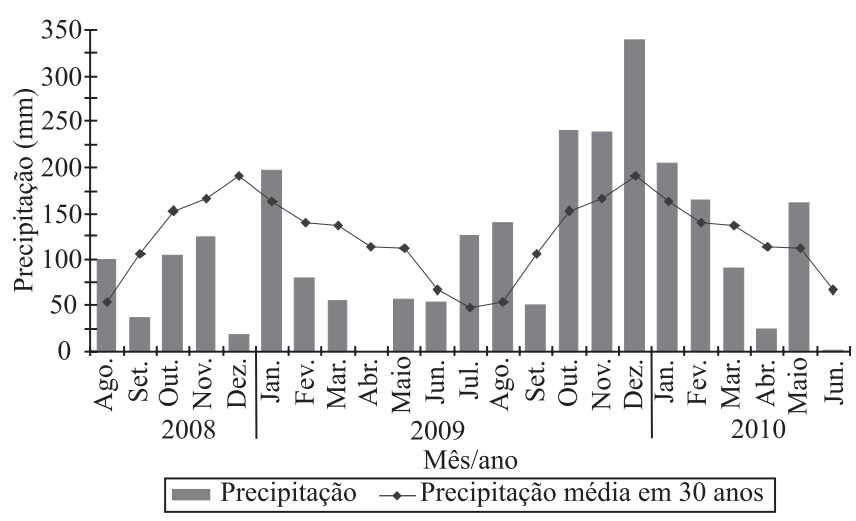

Figura 1. Precipitação pluviométrica mensal nas safras 2008/2009 e 2009/2010 e médias históricas de precipitação registradas na estação meteorológica da Embrapa Agropecuária Oeste, Dourados, MS. 
\& Dias (2008), uma vez que não há recomendação de adubação para a cultura do pinhão-manso. As espécies forrageiras não receberam adubação.

O manejo das espécies forrageiras foi realizado por meio de roçadas, com roçadeira costal, de acordo com a altura de manejo, indicada para cada espécie. O resíduo vegetal resultante da roçada foi distribuído uniformemente sobre a parcela. Foi determinada a produção de matéria seca da parte aérea e medida a altura das plantas em sete épocas: abril, julho, outubro e dezembro de 2009 e março, abril e junho de 2010.

A altura das espécies consorciadas foi medida da superfície do solo ao ápice da planta, com auxílio de trena graduada em mm, tendo-se amostrado dez plantas por parcela, antes de cada manejo. A produção de matéria seca da parte aérea foi determinada, por meio do corte das plantas, com auxílio de quadro de metal com área de $0,25 \mathrm{~m}^{2}$, em três pontos por parcela, quando as plantas atingiram a altura de manejo indicada para cada espécie: $20 \mathrm{~cm}$, Stylosanthes spp., U. ruziziensis, $U$. ruziziensis + Stylosanthes spp. e U. humidicola; $40 \mathrm{~cm}$, M. maximus; e $50 \mathrm{~cm}, C$. cajan e C. spectabilis. Não foi realizado o corte nas plantas que não atingiram a altura de manejo, tendo-se considerado, neste caso, a produção de matéria seca e o crescimento como nulos.

$\mathrm{Na}$ avaliação de junho de 2010, a produção de matéria seca de Stylosanthes spp. foi considerada zero, por não atingir a altura mínima de corte de $20 \mathrm{~cm}$. Em outubro de 2009, as espécies C. cajan e C. spectabilis não foram cortadas, para propiciar a produção de sementes, e a avaliação da produção de matéria seca foi considerada nula. Após a colheita das sementes, houve o rebrote das espécies e a produção de matéria seca foi quantificada em dezembro de 2009 e março de 2010 e, posteriormente, as plantas fecharam o ciclo bianual.

Após coleta no campo, o material foi levado para o laboratório para a medição da massa de matéria fresca, com auxílio de balança de precisão, e, posteriormente, à estufa de circulação forçada de ar a $65^{\circ} \mathrm{C}$, por 48 horas, para determinação da massa de matéria seca.

Os dados foram submetidos à análise de variância e as médias foram comparadas pelo teste Tukey, a 5\% de probabilidade, com uso do Sisvar (Ferreira, 2008). Foi realizado o desdobramento das interações duplas significativas.

\section{Resultados e Discussão}

Foram observadas diferenças significativas quanto à altura de plantas entre todas as espécies avaliadas, nas avaliações de abril, junho, outubro e dezembro de 2009 (Tabela 1). Na média dos sistemas de cultivo e épocas de avaliação, C. cajan $(79,43 \mathrm{~cm})$ e $M$. maximus $(76,85 \mathrm{~cm})$ foram os que apresentaram as maiores alturas de plantas.

Quando comparados os sistemas de cultivo, o sistema consorciado proporcionou maior altura de plantas (Tabela 1), na média das espécies e épocas $(63,80 \mathrm{~cm})$. Esses resultados podem ser atribuídos ao efeito de sombreamento, exercido pelo pinhão-manso. $\mathrm{Na}$ primeira avaliação, em abril de 2009 , o teste de médias demonstrou que o sistema de cultivo solteiro resultou em maior altura; nas avaliações de julho, outubro e dezembro de 2009, no entanto, o sistema consorciado apresentou as maiores médias e, para as

Tabela 1. Altura de plantas $(\mathrm{cm})$ das espécies forrageiras de acordo com a época de avaliação e sistema de cultivo, nas safras 2009 e $2010^{(1)}$.

\begin{tabular}{|c|c|c|c|c|c|c|c|c|}
\hline \multirow[t]{2}{*}{ Tratamento } & \multicolumn{4}{|c|}{2009} & \multicolumn{3}{|c|}{2010} & \multirow[t]{2}{*}{ Média } \\
\hline & Abril & Julho & Outubro & Dezembro & Março & Abril & Junho & \\
\hline & \multicolumn{8}{|c|}{ Espécie } \\
\hline Stylosanthes spp. & $22,41 \mathrm{e}$ & $33,08 \mathrm{~d}$ & $50,79 \mathrm{c}$ & $59,20 b$ & $69,58 \mathrm{a}$ & $36,90 \mathrm{~d}$ & $0,00 \mathrm{f}$ & $38,85 \mathrm{~F}$ \\
\hline Urochloa ruziziensis & $89,30 \mathrm{a}$ & $48,21 \mathrm{~d}$ & $59,76 \mathrm{c}$ & $72,29 b$ & $78,15 b$ & $62,08 \mathrm{c}$ & $43,95 \mathrm{~d}$ & $64,82 \mathrm{CD}$ \\
\hline U. ruziziensis + Stylosanthes spp. & $86,70 \mathrm{a}$ & $48,46 \mathrm{e}$ & $57,73 d$ & $73,46 \mathrm{bc}$ & $78,56 b$ & $68,98 \mathrm{c}$ & $44,58 \mathrm{e}$ & $65,49 \mathrm{C}$ \\
\hline U. humidicola & $42,96 \mathrm{~cd}$ & $28,13 \mathrm{e}$ & $47,01 \mathrm{c}$ & $81,22 \mathrm{a}$ & $57,73 b$ & $36,89 \mathrm{~d}$ & $29,61 \mathrm{e}$ & $46,22 \mathrm{E}$ \\
\hline Megathyrsus maximus & $46,26 f$ & $48,71 \mathrm{f}$ & $117,99 \mathrm{a}$ & $75,85 \mathrm{~d}$ & $99,16 b$ & $86,89 \mathrm{c}$ & $63,10 \mathrm{e}$ & $76,85 \mathrm{~B}$ \\
\hline Cajanus cajan & $125,89 \mathrm{c}$ & $105,29 d$ & $0,00 \mathrm{e}$ & $170,01 \mathrm{a}$ & $154,79 b$ & $0,00 \mathrm{e}$ & $0,00 \mathrm{e}$ & $79,43 \mathrm{~A}$ \\
\hline \multirow[t]{2}{*}{ Crotalaria spectabilis } & $95,50 \mathrm{c}$ & $83,04 d$ & $0,00 \mathrm{e}$ & $116,03 \mathrm{~b}$ & $143,11 \mathrm{a}$ & $0,00 \mathrm{e}$ & $0,00 \mathrm{e}$ & $62,53 \mathrm{D}$ \\
\hline & \multicolumn{8}{|c|}{ Sistema de cultivo } \\
\hline Solteiro & $79,91 \mathrm{~A}$ & $51,91 \mathrm{~B}$ & $39,67 \mathrm{~B}$ & $84,77 \mathrm{~B}$ & $97,63 \mathrm{~A}$ & $41,44 \mathrm{~A}$ & $26,43 \mathrm{~A}$ & $60,25 B$ \\
\hline Consórcio & $65,52 \mathrm{~B}$ & $60,93 \mathrm{~A}$ & $55,55 \mathrm{~A}$ & $100,39 \mathrm{~A}$ & $96,63 \mathrm{~A}$ & $41,90 \mathrm{~A}$ & $25,35 \mathrm{~A}$ & $63,80 \mathrm{~A}$ \\
\hline
\end{tabular}

${ }^{(1)}$ Médias seguidas de letras iguais, minúscula nas linhas e maiúscula nas colunas, não diferem entre si pelo teste de Tukey, a 5\% de probabilidade. 
avaliações em março de 2009, abril e junho de 2010, os sistemas não diferiram significativamente entre si.

O efeito do consórcio variou de acordo com o estágio fenológico das plantas (Tabela 2). No desdobramento da interação entre espécies e sistemas de cultivo, não houve diferença significativa entre os sistemas, para Stylosanthes spp. (Figura 2). Nos tratamentos com $U$. humidicola e C. cajan, as médias foram maiores no sistema solteiro. Nos demais tratamentos, a altura das plantas foi superior nos sistemas consorciados. A discrepância nos resultados pode ser explicada pela capacidade adaptativa diferencial das espécies, ao sombreamento. Megathyrsus maximus foi capaz de manter seu crescimento e produção de matéria seca, mesmo com o sombreamento causado pelo pinhão-manso. Embora Paciullo et al. (2008) afirmem que a presença de árvores reduz a luminosidade disponível e altera as características morfofisiológicas e a produtividade das pastagens, Porfírio-da-Silva (2006) relata que a presença de espécies arbóreas favorece o desenvolvimento destas, em razão da alteração de algumas variáveis microclimáticas.

No desdobramento da interação entre espécies forrageiras, sistemas de cultivo e épocas de avaliação, em abril de 2009 foram observadas as maiores alturas de plantas no sistema de cultivo solteiro, para todas as espécies (Tabela 2). Esse resultado pode ser explicado pela menor demanda hídrica das espécies no início de seu desenvolvimento, o que minimizaria um possível efeito benéfico do sombreamento sobre a economia de água, e pela menor luminosidade disponível no sistema consorciado, que teria possibilitado um desenvolvimento inicial mais lento das espécies, em comparação ao cultivo solteiro.

No entanto, pôde-se observar que, de forma geral apenas o crescimento inicial é prejudicado pelo consórcio e que, depois de estabelecidas - com exceção de M. maximus e U. humidicola-odesenvolvimento das espécies ou é favorecido pelo consórcio, ou este não o influencia significativamente. De acordo com Severino et al. (2006), espécies forrageiras costumam se adaptar ao sistema consorciado, com bom desenvolvimento mesmo sob baixa luminosidade. Paciullo et al. (2008) também verificaram que forrageiras se adaptam bem a ambientes com presença de arbóreas, que causam redução da luminosidade disponível.

A altura de plantas variou entre as avaliações, ao longo do ano, no sistema de cultivo solteiro, para todas as espécies (Tabela 2). Para U. ruziziensis, a maior altura foi observada em abril de 2009 e, para M. maximus, em outubro de 2009. No sistema consorciado, a maior altura de $M$. maximus também foi observada em outubro de 2009, enquanto que a de $U$. ruziziensise e C. cajan, em dezembro de 2009.

Tabela 2. Altura de plantas $(\mathrm{cm})$ das espécies forrageiras, com os efeitos desdobrados dentro de cada sistema de cultivo e cada época de avaliação, nas safras 2009 e $2010^{(1)}$.

\begin{tabular}{|c|c|c|c|c|c|c|c|}
\hline \multirow[t]{2}{*}{ Espécie } & \multicolumn{4}{|c|}{2009} & \multicolumn{3}{|c|}{2010} \\
\hline & Abril & Julho & Outubro & Dezembro & Março & Abril & Junho \\
\hline & \multicolumn{7}{|c|}{ Sistema de cultivo solteiro } \\
\hline Stylosanthes spp. & $27,00 \mathrm{Ae}$ & 31,00 Ade & $43,30 \mathrm{Bc}$ & $56,70 \mathrm{Ab}$ & $73,30 \mathrm{Aa}$ & $36,70 \mathrm{Acd}$ & - \\
\hline Urochloa ruziziensis & $101,00 \mathrm{Aa}$ & $44,67 \mathrm{Bd}$ & $36,70 \mathrm{Bd}$ & $60,00 \mathrm{Bc}$ & $81,70 \mathrm{Ab}$ & $60,00 \mathrm{Ac}$ & $45,00 \mathrm{Ad}$ \\
\hline U. ruziziensis + Stylosanthes spp. & $92,00 \mathrm{Aa}$ & $41,67 \mathrm{Bd}$ & $36,70 \mathrm{Bd}$ & $61,70 \mathrm{Bc}$ & $76,70 \mathrm{Ab}$ & $66,70 \mathrm{Ac}$ & $45,00 \mathrm{Ad}$ \\
\hline U. humidicola & $48,00 \mathrm{Ac}$ & $32,67 \mathrm{Ad}$ & $46,70 \mathrm{Ac}$ & $88,30 \mathrm{Aa}$ & $61,70 \mathrm{Ab}$ & $35,00 \mathrm{Ad}$ & $31,70 \mathrm{Ad}$ \\
\hline Megathyrsus maximus & $51,70 \mathrm{Ad}$ & $54,33 \mathrm{Acd}$ & $114,30 \mathrm{Ba}$ & $56,70 \mathrm{Bcd}$ & $85,00 \mathrm{Bb}$ & $91,70 \mathrm{Ab}$ & $63,30 \mathrm{Ac}$ \\
\hline Cajanus cajan & $137,70 \mathrm{Ab}$ & $97,00 \mathrm{Bc}$ & - & $176,70 \mathrm{Aa}$ & $185,00 \mathrm{Aa}$ & - & - \\
\hline \multirow[t]{2}{*}{ Crotalaria spectabilis } & $102,00 \mathrm{Ab}$ & $62,00 \mathrm{Bc}$ & - & $93,30 \mathrm{Bb}$ & $120,00 \mathrm{Ba}$ & - & - \\
\hline & \multicolumn{7}{|c|}{ Sistema de cultivo consorciado } \\
\hline Stylosanthes spp. & $17,83 \mathrm{Bc}$ & $35,17 \mathrm{Ab}$ & $58,28 \mathrm{Aa}$ & $61,70 \mathrm{Aa}$ & $65,85 \mathrm{Ba}$ & $37,10 \mathrm{Ab}$ & $0,00 \mathrm{Ad}$ \\
\hline Urochloa ruziziensis & $77,60 \mathrm{Bab}$ & $51,75 \mathrm{Ad}$ & $82,83 \mathrm{Aab}$ & $84,58 \mathrm{Aa}$ & $74,60 \mathrm{Bb}$ & $64,15 \mathrm{Ac}$ & $42,90 \mathrm{Ad}$ \\
\hline U. ruziziensis + Stylosanthes spp. & $81,40 \mathrm{Ba}$ & $55,25 \mathrm{Ac}$ & $78,75 \mathrm{Aab}$ & $85,23 \mathrm{Aa}$ & $80,43 \mathrm{Aab}$ & $71,25 \mathrm{Ab}$ & $44,15 \mathrm{Ad}$ \\
\hline U. humidicola & $37,93 \mathrm{Bd}$ & $22,58 \mathrm{Be}$ & $47,33 \mathrm{Abc}$ & $74,15 \mathrm{Ba}$ & $53,75 \mathrm{Bb}$ & 38,78 Acd & $27,53 \mathrm{Ae}$ \\
\hline Megathyrsus maximus & $40,83 \mathrm{Be}$ & $43,08 \mathrm{Be}$ & $121,68 \mathrm{Aa}$ & $95,00 \mathrm{Ab}$ & $113,33 \mathrm{Aa}$ & $82,08 \mathrm{Bc}$ & $62,90 \mathrm{Ad}$ \\
\hline Cajanus cajan & $114,08 \mathrm{Bc}$ & $113,58 \mathrm{Ac}$ & - & $163,33 \mathrm{Ba}$ & $124,58 \mathrm{Bb}$ & - & - \\
\hline Crotalaria spectabilis & $89,00 \mathrm{Bd}$ & $104,08 \mathrm{Ac}$ & - & $138,75 \mathrm{Ab}$ & $166,23 \mathrm{Aa}$ & - & - \\
\hline
\end{tabular}

${ }^{(1)}$ Médias seguidas de letras iguais, maiúscula nas colunas compara a mesma espécie entre sistemas e minúscula nas linhas, não diferem entre si pelo teste de Tukey, a $5 \%$ de probabilidade. 
No período de outono/inverno, a menor precipitação e intensidade luminosa, associadas a baixas temperaturas, resultaram em menor crescimento das espécies, em comparação ao período de primavera/ verão. Resultados semelhantes foram observados por Gimenes et al. (2011), que relataram alturas de pastejo do capim-marandu no período de outono/ inverno abaixo da meta estabelecida, e atribuíram esse

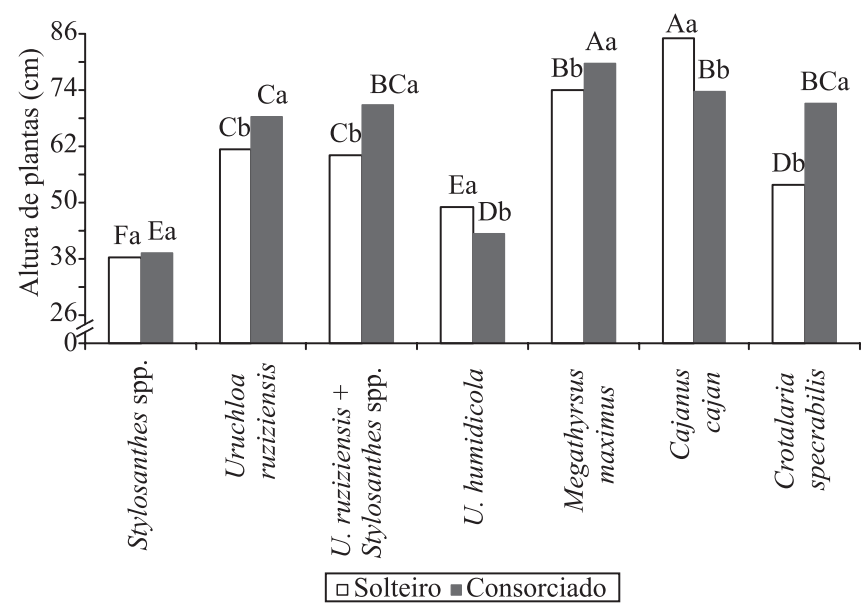

Figura 2. Altura das espécies forrageiras, obtidas nas safras 2008/2009 e 2009/2010 em sistema solteiro e consorciado com pinhão manso. Médias seguidas de letras iguais, minúscula para sistemas em cada cultivar e maiúscula entre cultivares no mesmo sistema de cultivo, não diferem pelo teste de Tukey, a 5\% de probabilidade. resultado à baixa taxa de acúmulo de forragem durante o período frio e seco do ano.

A produtividade de matéria seca das espécies variou de acordo com os sistemas de cultivo (Tabela 3). Megathyrsus maximus e C. spectabilis tiveram sua produtividade de matéria seca favorecida, em algumas épocas, pelo sistema consorciado.

Todas as espécies estudadas apresentaram boa produção de palhada, acima de $12 \mathrm{Mg} \mathrm{ha}^{-1}$ de matéria seca (Tabela 4), valor indicado como ideal para plantio direto na região do Cerrado (Séguy et al., 1995; Alvarenga et al., 2001). Segundo Stone (2001), essa produção de matéria seca pode auxiliar na estruturação do solo. De fato, a produção de palhada em solos com textura arenosa é fundamental para proteção contra a perda de água e superaquecimento. $\mathrm{O}$ aporte de resíduos orgânicos sobre o solo, em médio e longo prazos, pode aumentar o teor de matéria orgânica no solo, que é a principal responsável pela CTC em solos arenosos (Stone, 2001; Laviola \& Dias, 2008).

A produtividade de matéria seca foi influenciada pelo sistema de cultivo. Megathyrsus maximus e C. spectabilis foram as únicas espécies que tiveram suas produtividades aumentadas pelo sistema consorciado (Figura 3). Neste sistema, foi observado que $M$. maximus apresentou a maior produtividade de matéria seca, seguido por U. ruziziensis e U. ruziziensis

Tabela 3. Produtividade de matéria seca da parte aérea $\left(\mathrm{Mg} \mathrm{ha}^{-1}\right)$ das espécies forrageiras, com os efeitos desdobrados dentro de cada sistema de cultivo e cada época de avaliação, nas safra 2009 e $2010^{(1)}$.

\begin{tabular}{|c|c|c|c|c|c|c|c|}
\hline \multirow[t]{2}{*}{ Espécie } & \multicolumn{4}{|c|}{2009} & \multicolumn{3}{|c|}{2010} \\
\hline & Abril & Julho & Outubro & Dezembro & Março & Abril & Junho \\
\hline & \multicolumn{7}{|c|}{ Sistema de cultivo solteiro } \\
\hline Stylosanthes spp. & $1,66 \mathrm{Abc}$ & $1,83 \mathrm{Abc}$ & $6,36 \mathrm{Aa}$ & $5,51 \mathrm{Aa}$ & $2,88 \mathrm{Ab}$ & $2,48 \mathrm{Ab}$ & - \\
\hline Urochloa ruziziensis & $4,83 \mathrm{Ab}$ & $1,77 \mathrm{Bc}$ & $4,02 \mathrm{Bb}$ & $3,09 \mathrm{Bbc}$ & $8,58 \mathrm{Aa}$ & $4,96 \mathrm{Ab}$ & $1,24 \mathrm{Ac}$ \\
\hline U. ruziziensis + Stylosanthes spp. & $5,77 \mathrm{Aa}$ & $1,67 \mathrm{Bcd}$ & $4,61 \mathrm{Bab}$ & $5,01 \mathrm{Aab}$ & $5,70 \mathrm{Aa}$ & $3,23 \mathrm{Abc}$ & $1,19 \mathrm{Ad}$ \\
\hline U. humidicola & $3,34 \mathrm{Abc}$ & $1,17 \mathrm{Ad}$ & 4,12Aab & 4,79Aab & $5,98 \mathrm{Aa}$ & $1,81 \mathrm{Acd}$ & $0,63 \mathrm{Ad}$ \\
\hline Megathyrsus maximus & $3,39 \mathrm{Abc}$ & $2,85 \mathrm{Ac}$ & $9,40 \mathrm{Aa}$ & $4,80 \mathrm{Bb}$ & $3,93 \mathrm{Bbc}$ & $3,17 \mathrm{Abc}$ & $0,75 \mathrm{Ad}$ \\
\hline Cajanus cajan & $2,86 \mathrm{Ab}$ & $3,94 \mathrm{Ab}$ & - & $10,15 \mathrm{Aa}$ & $11,06 \mathrm{Aa}$ & - & - \\
\hline \multirow[t]{2}{*}{ Crotalaria spectabilis } & $1,35 \mathrm{Acd}$ & $2,34 \mathrm{Bbc}$ & - & 4,22Bab & $6,07 \mathrm{Ba}$ & - & - \\
\hline & \multicolumn{7}{|c|}{ Sistema de cultivo consorciado } \\
\hline Stylosanthes spp. & $0,23 \mathrm{Bc}$ & $1,55 \mathrm{Abc}$ & $6,12 \mathrm{Aa}$ & $5,88 \mathrm{Aa}$ & $3,20 \mathrm{Ab}$ & $3,11 \mathrm{Ab}$ & \\
\hline Urochloa ruziziensis & $2,83 \mathrm{Bb}$ & $3,16 \mathrm{Ab}$ & $7,16 \mathrm{Aa}$ & $6,45 \mathrm{Aa}$ & $4,44 \mathrm{Bb}$ & $2,79 \mathrm{Bb}$ & 0,79Ac \\
\hline U. ruziziensis + Stylosanthes spp. & $3,22 \mathrm{Bb}$ & $3,28 \mathrm{Ab}$ & $6,11 \mathrm{Aa}$ & $6,09 \mathrm{Aa}$ & $2,83 \mathrm{Bb}$ & $2,82 \mathrm{Ab}$ & $0,82 \mathrm{Ac}$ \\
\hline U. humidicola & $0,70 \mathrm{Bc}$ & $0,68 \mathrm{Ac}$ & $4,59 \mathrm{Aa}$ & $4,76 \mathrm{Aa}$ & $2,85 \mathrm{Bab}$ & $2,08 \mathrm{Abc}$ & $0,70 \mathrm{Ac}$ \\
\hline Megathyrsus maximus & $2,18 \mathrm{Abc}$ & $3,54 \mathrm{Ab}$ & $8,32 \mathrm{Aa}$ & $7,85 \mathrm{Aa}$ & $7,80 \mathrm{Aa}$ & $4,06 \mathrm{Ab}$ & $1,39 \mathrm{Ac}$ \\
\hline Cajanus cajan & $1,13 \mathrm{Bbc}$ & $4,65 \mathrm{Aa}$ & - & $4,93 \mathrm{Ba}$ & $1,95 \mathrm{Bb}$ & - & - \\
\hline Crotalaria spectabilis & $0,86 \mathrm{Ac}$ & $5,97 \mathrm{Ab}$ & - & $5,63 \mathrm{Ab}$ & $9,28 \mathrm{Aa}$ & - & - \\
\hline
\end{tabular}

${ }^{(1)}$ Médias seguidas de letras iguais, maiúscula nas colunas compara a mesma espécie entre sistemas de cultivo e minúsculas na linha comparam avaliações para cada espécie, não diferem entre si pelo teste de Tukey, a 5\% de probabilidade. 
+ Stylosanthes spp. A elevada produtividade dessas espécies, mesmo em cultivo consorciado ao pinhão-manso, demonstra sua capacidade de manter o crescimento, mesmo com restrição de luz (Severino et al., 2006).

Nas avaliações de abril de 2009 e março de 2010, as espécies produziram maior quantidade de matéria seca no sistema solteiro (Tabela 4). Nas avaliações entre julho e dezembro de 2009, a maior produtividade foi observada no sistema consorciado. Nas demais avaliações, não houve diferença entre os sistemas.

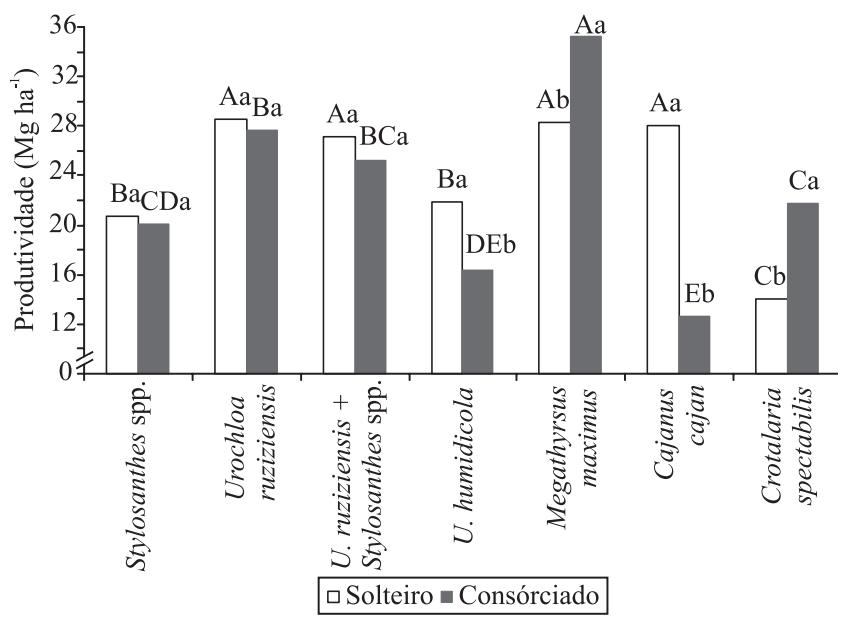

Figura 3. Produtividade de matéria seca de diferentes espécies forrageiras, obtidas nas safras 2008/2009 e 2009/2010, em sistema solteiro e consorciado com pinhão manso. Médias seguidas de letras iguais, minúscula para sistemas em cada cultivar e maiúscula entre cultivares no mesmo sistema de cultivo, não diferem, entre si, pelo teste de Tukey, a 5\% de probabilidade.
No período de dezembro de 2009 a março de 2010 , o consórcio favoreceu a produção de matéria seca de M. maximus (Tabela 3). Nos demais períodos, a produtividade não variou entre os sistemas para essa espécie. Crotalária spectabilis também teve sua produtividade de matéria seca favorecida, em alguns períodos, pelo sistema de cultivo consorciado. Isso indica que essas espécies apresentam bom potencial para serem cultivadas em consórcio. O sombreamento parcial pode ter induzido essas espécies ao maior desenvolvimento e acúmulo de matéria seca, por favorecer maior retenção de umidade no solo. Andrade et al. (2004), ao avaliar a taxa de acúmulo de matéria seca de diferentes espécies forrageiras, verificaram efeito indireto benéfico do sombreamento pela redução do estresse hídrico durante o período seco, com diminuição da estacionalidade de produção das gramíneas forrageiras. Segundo os autores, quanto maior o sombreamento, menor a diferença entre as taxas de acúmulo de matéria seca entre os períodos chuvoso e seco. Como exemplo, eles relatam que, com $70 \%$ de sombra, o M. maximus apresentou maior crescimento no período seco.

Em C. cajan, o consórcio com pinhão-manso resultou na menor produtividade em todos os períodos em que a avaliação foi possível (Tabela 3), evidência de que essa espécie não tolera bem o sombreamento.

As espécies poáceas apresentaram boa distribuição da produção de matéria seca ao longo do ano, no sistema consorciado (Tabela 3), inclusive nos períodos frio e seco do ano, em que as espécies apresentam menor taxa de acúmulo de forragem (Gimenes et al., 2011). Essa menor variação sazonal na produção de matéria

Tabela 4. Produtividade de matéria seca da parte aérea $\left(\mathrm{Mg} \mathrm{ha}^{-1}\right)$ de acordo com as espécies e com os sistemas de cultivo avaliados, em diferentes épocas, nas safras 2009 e 2010.

\begin{tabular}{|c|c|c|c|c|c|c|c|c|}
\hline \multirow[t]{2}{*}{ Tratamento } & \multicolumn{4}{|c|}{2009} & \multicolumn{3}{|c|}{2010} & \multirow[t]{2}{*}{ Total } \\
\hline & Abril & Julho & Outubro & Dezembro & Março & Abril & Junho & \\
\hline & \multicolumn{8}{|c|}{ Espécies } \\
\hline Stylosanthes spp. & $0,94 \mathrm{~cd}$ & $1,69 \mathrm{bc}$ & $6,24 \mathrm{a}$ & $5,70 \mathrm{a}$ & $3,04 \mathrm{~b}$ & $2,79 b$ & $0,00 \mathrm{~d}$ & $20,40 \mathrm{C}$ \\
\hline Urochloa ruziziensis & $3,83 \mathrm{~cd}$ & $2,47 \mathrm{a}$ & $5,59 \mathrm{ab}$ & $4,77 \mathrm{bc}$ & $6,51 \mathrm{a}$ & $3,88 \mathrm{c}$ & $1,02 \mathrm{e}$ & $28,07 \mathrm{~B}$ \\
\hline U. ruziziensis + Stylosanthes spp. & $4,50 \mathrm{a}$ & $2,48 \mathrm{c}$ & $5,36 \mathrm{a}$ & $5,55 \mathrm{a}$ & $4,27 \mathrm{ab}$ & $3,03 \mathrm{bc}$ & $1,01 \mathrm{~d}$ & $26,18 \mathrm{~B}$ \\
\hline U. humidicola & $2,02 b$ & $0,93 b$ & $4,35 \mathrm{a}$ & $4,77 \mathrm{a}$ & $4,41 \mathrm{a}$ & $1,94 \mathrm{~b}$ & $0,66 b$ & $19,10 \mathrm{C}$ \\
\hline Megathyrsus maximus & $2,78 \mathrm{c}$ & $3,19 \mathrm{c}$ & $8,86 \mathrm{a}$ & $6,33 b$ & $5,86 \mathrm{~b}$ & $3,61 \mathrm{c}$ & $1,08 \mathrm{~d}$ & $31,71 \mathrm{~A}$ \\
\hline Cajanus cajan & $1,99 \mathrm{c}$ & $4,15 b$ & $0,00 \mathrm{~d}$ & $7,54 \mathrm{a}$ & $6,50 \mathrm{a}$ & $0,00 \mathrm{~d}$ & $0,00 \mathrm{~d}$ & $20,33 \mathrm{C}$ \\
\hline \multirow[t]{2}{*}{ Crotalaria spectabilis } & $1,11 \mathrm{c}$ & $4,30 \mathrm{~b}$ & $0,00 \mathrm{c}$ & $4,92 \mathrm{~b}$ & $7,68 \mathrm{a}$ & $0,00 \mathrm{~d}$ & $0,00 \mathrm{c}$ & $17,87 \mathrm{C}$ \\
\hline & \multicolumn{8}{|c|}{ Sistemas de cultivo } \\
\hline Solteiro & $3,31 \mathrm{~A}$ & $2,23 \mathrm{~B}$ & $4,07 \mathrm{~B}$ & $5,37 \mathrm{~B}$ & $6,31 \mathrm{~A}$ & $2,24 \mathrm{~A}$ & $0,54 \mathrm{~A}$ & $24,08 \mathrm{~A}$ \\
\hline Consórcio & $1,59 \mathrm{~B}$ & $3,26 \mathrm{~A}$ & $4,61 \mathrm{~A}$ & $5,94 \mathrm{~A}$ & $4,62 \mathrm{~B}$ & $2,12 \mathrm{~A}$ & $0,53 \mathrm{~A}$ & $22,68 \mathrm{~B}$ \\
\hline
\end{tabular}

${ }^{(1)}$ Médias seguidas de letras iguais, minúscula nas linhas e maiúscula nas colunas, não diferem entre si pelo teste de Tukey, a $5 \%$ de probabilidade. 
seca possivelmente está relacionada à melhoria da fertilidade do solo e à maior retenção de água no solo, no cultivo consorciado, causados pela decomposição das folhas do pinhão-manso (Laviola \& Dias, 2008) e pela adição da matéria seca ao solo pelas espécies forrageiras (Stone, 2001).

A menor produtividade de matéria seca nos cultivos consorciados, na primeira avaliação (Tabela 4), está relacionada ao sombreamento excessivo, o que prejudica o crescimento inicial das forrageiras (Dias-filho, 2007).

No sistema consorciado, verificou-se menor estacionalidade de produção de matéria seca de Stylosanthes spp., U. ruziziensis, U. ruziziensis + Stylosanthes spp., U. humidicola e M. maximus, especialmente entre julho de 2009 e março de 2010 (Tabela 3). Esse comportamento está relacionado às possíveis melhorias nas condições de fertilidade e umidade propiciadas pelo consórcio.

\section{Conclusões}

1. As espécies avaliadas apresentam boa capacidade produtiva, para uso como forrageiras ou cobertura do solo, em consórcio com pinhão-manso.

2. Megathyrsus maximus cultivarMassaiapresentamaior capacidade produtiva e tolerância ao sombreamento que as demais espécies, quando consorciado com pinhão-manso.

\section{Agradecimentos}

À Embrapa Agropecuária Oeste, à Fundação de Apoio ao Desenvolvimento do Ensino, Ciência e Tecnologia do Estado de Mato Grosso do Sul, à Fazenda Paraíso, à Petrobras, à Financiadora de Estudos e Projetos e ao Conselho Nacional de Desenvolvimento Científico e Tecnológico, pelo apoio financeiro e concessão de bolsa de estudo.

\section{Referências}

ALVARENGA, R.C.; LARA CABEZAS, W.A.; CRUZ, J.C.; SANTANA, D.P. Plantas de cobertura de solo para sistema plantio direto. Informe Agropecuário, v.22, p.25-36, 2001.

ANDRADE, C.M.S. de; GARCIA, R.; COUTO, L.; PEREIRA, O.G.; SOUZA, A.L. de. Desempenho de seis gramíneas solteiras ou consorciadas com o Stylosanthes guianensis cv. Mineirão e eucalipto em sistema silvipastoril. Revista Brasileira de Zootecnia, v.32, p.1845-1850, 2003.
ANDRADE, C.M.S. de; VALENTIM, J.F.; CARNEIRO, J. da C.; VAZ, F.A. Crescimento de gramíneas e leguminosas forrageiras tropicais sob sombreamento. Pesquisa Agropecuária Brasileira, v.39, p.263-270, 2004.

DIAS-FILHO, M.B. Degradação de pastagens: processos, causas e estratégias de recuperação. 3.ed. Belém: Embrapa Amazônia Oriental, 2007. 190p.

DIAS-FILHO, M.B. Growth and biomass allocation of the C4 grasses Brachiaria brizantha and Brachiaria humidicola under shade. Pesquisa Agropecuária Brasileira, v.35, p.2335-2341, 2000.

FAGERIA, N.K.; STONE, L.F. Produtividade de feijão no sistema plantio direto com aplicação de calcário e zinco. Pesquisa Agropecuária Brasileira, v.39, p.73-78, 2004.

FERREIRA, D.F. SISVAR: um programa para análises e ensino de estatística. Revista Symposium, v.6, p.36-41, 2008.

GIMENES, F.M. de A.; SILVA, S.C. da; FIALHO, C.A.; GOMES, M.B.; BERNDT, A.; GERDES, L.; COLOZZA, M.T. Ganho de peso e produtividade animal em capim-marandu sob pastejo rotativo e adubação nitrogenada. Pesquisa Agropecuária Brasileira, v.46, p.751-759, 2011.

LAVIOLA, B.G.; DIAS, L.A. dos S. Teor e acúmulo de nutrientes em folhas e frutos de pinhão-manso. Revista Brasileira de Ciência do Solo, v.32, p.1969-1975, 2008.

MÜLLER, M. Produção consorciada de alimentos e energia pela agricultura familiar: cultivo de oleaginosas perenes. Panorama do Leite, n.20, 2008. Disponível em: <http://www.cileite.com.br/ panorama/especial20.html>. Acesso em: 24 ago. 2011.

PACIULLO, D.S.C.; CAMPOS, N.R.; GOMIDE, C.A.M.; CASTRO, C.R.T. de; TAVELA, R.C.; ROSSIELlO, R.O.P. Crescimento de capim-braquiária influenciado pelo grau de sombreamento e pela estação do ano. Pesquisa Agropecuária Brasileira, v.43, p.917-923, 2008.

PORFÍRIO-DA-SILVA, V. Arborização de pastagens: I - procedimentos para introdução de árvores em pastagens convencionais. Colombo: Embrapa Florestas, 2006. 8 p. (Embrapa Florestas. Comunicado técnico, 155).

SÉGUY, L.; BOUZINAC, S.; MATSUBARA, M. Gestão dos solos e das culturas nas áreas de fronteiras agrícolas dos cerrados úmidos e das florestas do Centro-Oeste brasileiro - região Centro Norte do Mato Grosso. Lucas do Rio Verde: CIRAD, 1995. 259p.

SEVERINO, F.J.; CARVALHO, S.J.P.; CHRISTOFFOLETI, P.J. Interferências mútuas entre a cultura do milho, espécies forrageiras e plantas daninhas em um sistema de consórcio. II - implicações sobre as espécies forrageiras. Planta Daninha, v.24, p.45-52, 2006.

STONE, L.F; SILVEIRA, P.M. da. Efeitos do sistema de preparo e da rotação de culturas na porosidade e densidade do solo. Revista Brasileira de Ciência do Solo, v.25, p.395-400, 2001.

Recebido em 29 de setembro de 2011 e aprovado em 14 de fevereiro de 2012 